\title{
Investigation of the blood plasma depletome from schizophrenia patients and their association to quetiapine efficacy
}

\section{Licia C. S. Costa*, Sheila Garcia, Paulo A. Baldasso, Daniel Martins-de-Souza}

\begin{abstract}
Schizophrenia is a chronic and multifactorial disorder. The main way of controlling its symptoms is through antipsychotics. The human blood plasma is a potential source for biomarkers that predict medication efficacy. The removal of high-abundant proteins from plasma in order to reduce its complexity in terms of proteome may carry away potential biomarkers. Therefore, the analysis of the high-abundant proteins fraction (the depletome) can address this issues. We investigated the depletome of schizophrenia patients before the antipsychotic treatment using shotgun mass spectrometry approach. We identified 220 proteins in the depletome. These proteins show the importance of studying high abundant proteins in the quest for biomarkers.
\end{abstract}

\section{Key words:}

Schizophrenia, biomarkers, proteomics

\section{Introduction}

The main way of controlling schizophrenia symptoms is through antipsychotics. But there are no biomarkers that predict a successful response to medication ${ }^{1}$.This answer may be found in the blood plasma proteome ${ }^{2}$. Given the large dynamic range of blood plasma proteins, high abundant proteins (the depletome) are selectively depleted prior to proteome analysis. But during this process, potential biomarkers of low abundance may be removed inadvertently ${ }^{3}$. Thus, the analysis of the depletome $e^{4}$ is certainly a relevant question in the quest for biomarkers. Our study aims to investigate the depletome obtained from good and poor antipsychotic responders before the initiation of antipsychotic treatment using shotgun mass spectrometry ${ }^{5}$.

\section{Results and Discussion}

The analysis of good and poor responder groups in T0 (before the treatment) using shotgun mass spectrometry resulted in identification of 220 proteins and quantitation of 175 proteins. Over 50 were identified by 1 unique peptide if it had been counted at least 4 times in a given run. There are several biological process in which depletome proteins may be involved (Chart 1).

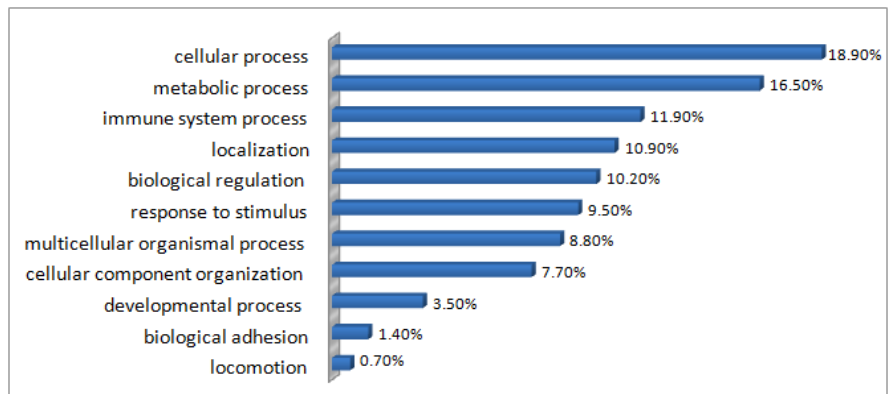

Chart 1. Biological process depletome proteins are involved in.

Five differentially expressed proteins were found between good and poor responders (Table 1). They were characterized using the Human Protein Reference Database (HPRD). These proteins are involved in several biological pathways, such signal transduction and vesiclemediated transport.
Table 1. Differentially expressed proteins classification

\begin{tabular}{|l|l|l|l|} 
Accession & Description & $\begin{array}{l}\text { Molecular } \\
\text { Function }\end{array}$ & $\begin{array}{l}\text { Biological } \\
\text { Process }\end{array}$ \\
\hline P19652 & $\begin{array}{l}\text { Alpha-1-acid } \\
\text { glycoprotein }\end{array}$ & $\begin{array}{l}\text { Defente } \\
\text { immunity protein } \\
\text { activity }\end{array}$ & $\begin{array}{l}\text { Immune } \\
\text { response }\end{array}$ \\
\hline P00739 & $\begin{array}{l}\text { Haptoglobin- } \\
\text { related protein }\end{array}$ & $\begin{array}{l}\text { Molecular } \\
\text { function unknown }\end{array}$ & $\begin{array}{l}\text { Immune } \\
\text { response }\end{array}$ \\
\hline P06727 & $\begin{array}{l}\text { Apolipoprotein } \\
\text { A-IV }\end{array}$ & $\begin{array}{l}\text { Transporter } \\
\text { activity }\end{array}$ & Transport \\
\hline P04433 & $\begin{array}{l}\text { Ig kappa } \\
\text { variable 3-11 }\end{array}$ & Uncharacterized & Uncharacterized \\
\hline P01624 & $\begin{array}{l}\text { Ig kappa } \\
\text { variable 3-15 }\end{array}$ & Uncharacterized & Uncharacterized \\
\hline
\end{tabular}

\section{Conclusions}

The blood plasma depletome revealed over 50 proteins, which participate in several biological processes. Five of the differentially expressed proteins play roles in protein signaling and drug vesicle-mediated transport. Thus, these proteins may be targets to compose a biomarkers panel in the future.

\section{Acknowledgement}

This research is funded by FAPESP, CNPq and CAPES.

(1) Guest, P.C.; Martins-de-Souza, D.; Schwarz, E.; Rahmoune, H.; Alsaif, M.; Tomasik, J.; Turck, C.W.; Bahn, S. Proteomic Profiling in Schizophrenia: Enabling Stratification for More Effective Treatment. Genome Med. 2013,5, 25.

(2) Geyer, P. E.; Kulak, N. A.; Pichler, G.; Holdt, L. M.; Teupser, D.; Mann, M. Plasma Proteome Profiling to Assess Human Health and Disease. Cell Syst 2016, 2, 185-195.

(3) Jaros, J. A. J.; Guest, P. C.; Bahn, S.; Martins-de-Souza, D. Affinity Depletion of Plasma and Serum for Mass Spectrometry-Based Proteome Analysis. Methods Mol. Biol. 2013, 1002, 1-11.

(4) Koutroukides, T.A.; Guest, P.C.; Leweke, F.M.; Bailey, D.M.D.; Rahmoune, H.; Bahn, S.; Martins-de-Souza, D. Characterization of the Human Serum Depletome by Label-Free Shotgun Proteomics. J.Sep.Sci. 2011, 34, 1621-1626. (5) Garcia, S.; Silva-Costa, L. C.; Reis-de-Oliveira, G.; Guest, P. C.; Baldasso, P. A.; Cassoli, J. S.; Martins-de-Souza, D. Identifying Biomarker Candidates in the Blood Plasma or Serum Proteome. In Advances in Experimental Medicine and Biology; 2017; pp. 193-203. 